\title{
ASSOCIATION OF SELECTED RISK FACTORS OF CORONARY HEART DISEASE WITH LIPID PROFILE
}

\author{
TRILOCHAN SAHU1 ${ }^{1}$, LIPILEKHA PATNAIK ${ }^{*}$, VENKATA RAO E ${ }^{1}$, SUBHASHREE RAY ${ }^{2}$, \\ SANDEEP KUMAR PANIGRAHI ${ }^{1}$
}

${ }^{1}$ Department of Community Medicine, Institute of Medical Sciences and Sum Hospital, Siksha '0' Anusandhan (Deemed to be University), Khordha, Bhubaneswar - 751 003, Odisha, India. ${ }^{2}$ Department of Biochemistry, Institute of Medical Sciences and SUM Hospital, Siksha '0' Anusandhan University, Khordha, Bhubaneswar - 751 003, Odisha, India.

Email: drlipilekha@yahoo.co.in

Received: 23 September 2017, Revised and Accepted: 22 November 2017

ABSTRACT

Objective: The objectives of this study is to assess the association of selected risk factors for coronary heart disease (CHD) with lipid profile.

Methods: A cross-sectional study was conducted during May 2013-April 2014 among 350 subjects of 25-64 years selected by systematic random sampling. Data on sociodemographic and medical and personal history along with anthropometric measurements were collected through house-tohouse visit. Blood sample was analyzed for fasting blood sugar and lipid profile.

Results: In this study, 38.58\% belong to the age group of 25-35 years and 58\% were female. Majority (45.43\%) of the participants belonged to lower socioeconomic status, followed by the middle (40.57\%) and upper class (14\%). It was observed that total cholesterol was significantly associated with blood sugar $(\mathrm{p}=0.0008)$, blood pressure $(\mathrm{p}=0.001)$, and body mass index (BMI) $(\mathrm{p}=0.018)$. There was no significant association among the risk factors of CHD such as smoking and alcohol with total cholesterol. Low-density lipoprotein level was significantly associated with BMI ( $\mathrm{p}=0.0001$ ) and blood sugar $(\mathrm{p}=0.003)$. There was a significant association among the risk factors for CHD such as smoking ( $\mathrm{p}=0.002)$, alcohol, $(\mathrm{p}=0.017)$ blood sugar $(\mathrm{p}=0.004)$, and BMI $(\mathrm{p}=0.014)$ with triglyceride level.

Conclusion: It was concluded from this study that various risk factors for CHD were associated with lipid abnormalities. Hence, a community-based education in this regard is of paramount importance.

Keywords: Body mass index, Coronary heart disease risk factors, Cholesterol, Dyslipidemia.

(C) 2018 The Authors. Published by Innovare Academic Sciences Pvt Ltd. This is an open access article under the CC BY license (http://creativecommons. org/licenses/by/4. 0/) DOI: http://dx.doi.org/10.22159/ajpcr.2018.v11i2.22667

\section{INTRODUCTION}

Irrespective of the vast progress made in the identification of the etiology and the treatment of cardiovascular diseases, people are still becoming prey to these diseases in developing countries like India. It was observed by the World Health Organization that, by the year 2020, coronary heart disease (CHD) and stroke would occupy the first and fourth places as the leading causes of disability and mortality. It was estimated that the incidence of coronary vascular diseases would increase from 2.90 crore in 2002 to about 6.40 crore in 2015. The etiology of CHD is multifactorial [1]. Together with elevated blood pressure, obesity, and diabetes mellitus, dyslipidemia is a component of the metabolic syndrome and associated with increased CHD risk [2]. Smoking which is recognized as a major risk factor for the development of ischemic heart disease may lead to altering the normal plasma lipoprotein pattern. An earlier study showed that increased cholesterol levels and CHD are observed in smokers [3]. The study also showed a strong synergistic interaction exists between hypercholesterolemia and tobacco consumption in the genesis of CHD [1]. CHD is increasingly seen in younger age groups among diabetics [4]. Lipid profiles in people with diabetes tend to be characterized by elevated very low-density lipoprotein (LDL), LDL, and high-density lipoprotein (HDL). People with diabetes and a raised cholesterol level experience greater risk of heart disease. Overweight increases the risk of having a heart disease because obese people are more likely to have hypertension, diabetes, and high levels of bad cholesterols [5]. Association of lipid profile with risk factors of CHD such as smoking, diabetes, obesity, hypertension, and history of alcoholism has not been explored in this area. Thus, the present study was conducted to find the association of different lipid components to CHD risk factors.

\section{METHODS}

Study setting

The study was conducted in the Urban Health and Training Centre (UHTC), functioning under the Department of Community Medicine.

\section{Sample size}

Population in the age group of 25-64 were 3459 as identified in the study area was considered as the study universe. Studies published earlier [6] on the determination of prevalence of CHD risk factors in urban Indian population have revealed that the most common dyslipidemia was low HDL to the tune of 54\%. Using this prevalence, sample size was calculated using $4 \mathrm{pq} / \mathrm{L}^{2}$ formula with $10 \%$ error, which was found to be 341 . Thus, a sample was rounded off to 350 .

\section{Sampling}

Systematic random sampling was used to arrive at the required sample size. Samples were selected from house-to-house visit. It was considered that at any given point of time at least two members would be present. Sampling interval was 12 and every $12^{\text {th }}$ house was visited after selecting the first house randomly. Study subjects who were found eligible and were present during the house-to-house visit were included in the study till a total of 350 subjects were reached. In case of a locked house, the next door household was considered for the study. 


\section{Study design}

It was a community-based cross-sectional study where a pre-designed and pre-tested questionnaire was used to collect information with respect to sociodemographic profile, and history of smoking, alcohol, and diabetes was collected. Their height, weight, and blood pressure were recorded. The information was collected by the social worker, whereas interns helped in the physical examination during door-todoor survey. The laboratory technician collected blood for investigations such as fasting blood sugar and lipid profile of all study subjects which sent immediately to the laboratory of IMS and SUM hospital for analysis.

\section{Study instrument}

The questionnaire was finalized after pre-testing in the field on ten subjects with refinement at different stages of preparation. The questionnaire was prepared by following WHO STEPS approach.

\section{Study duration}

The study has been conducted for 1 year from May 2013 to April 2014.

\section{Data analysis}

The data were analyzed using SPSS $(20.0 \mathrm{v})$ software. Outcome variables were expressed as percentages. Proportions were compared using Chisquare test. A p $<0.05$ was considered as statistically significant.

\section{Ethical considerations}

The detailed study protocol was submitted to the Institutional Ethics Committee of IMS and SUM Hospital and the approval was obtained. An informed written consent was obtained from each study participant before conducting the survey. Before obtaining the consent, the participants were explained in detail about the procedure in the local vernacular language, and their participation was voluntary. All the participants were provided appropriate advice and referral services at UHTC and SUM Hospital following evaluation of clinical and laboratory findings. Methods adopted during survey are as follows: Educational status: Categorization of the educational status was done according to the following criteria. Illiterate: An illiterate person was considered to be one who could not read and write or a person who could merely read but could nt write. Lower primary: A person who had done his/her schooling up to $4^{\text {th }}$ class. Upper primary: A person who had done his/her schooling up to or anywhere between $4^{\text {th }}$ and $8^{\text {th }}$ classes. Secondary: A person who had done his/her schooling up to or anywhere between $9^{\text {th }}$ or $10^{\text {th }}$ class. Higher secondary: A person who had done his/her schooling up to or anywhere between $11^{\text {th }}$, $12^{\text {th }}$ class or/and diploma. Graduate and above: A person who had done his/her graduation and above. Socioeconomic status (SES): For the assessment of social class, Prasad's classification was used. To update this classification, the All India Consumer Price Index for the year, 2013, was considered when the value was fixed at 1075 [7]. Social Class I and II labeled as upper class, social class III as middle, and social class IV and V as lower.

\section{Height}

The measuring scale (fiber tape) used to mark the values on the wall. After removal of the shoes, the study subject was made to stand on a flat floor against the scale with feet parallel and with heels, buttock, shoulder, and back of head touching upright by placing a scale horizontally on the head is used to measure the height.

\section{Weight}

To measure weight, an electronic weighing machine was used. The patients were weighed without any footwear. Body mass index (BMI) was calculated as weight $(\mathrm{kg})$ divided by height squared $\left(\mathrm{mt}^{2}\right)$ and interpreted as follows. BMI $\geq 25$ was taken as overweight/obese. Blood pressure: Using a sphygmomanometer, blood pressure of the study participants was checked in sitting position. If the participant is anxious, asked to wait for few minutes before taking blood pressure. Participants with a history of treatment for hypertension, having a systolic blood pressure $\geq 140$ or diastolic blood pressure $\geq 90$, or both were considered as hypertension.

\section{Smoking}

Participants who smoked at least 100 cigarettes in their lifetime and at the time of interview smoke every day or some days were considered as a smoker.

Alcohol

Person consuming five drinks or more on 1 day in 1 month was considered as a risk factor for CHD in this study.

\section{Laboratory investigations}

Blood samples are collected from all the participants with a disposable syringe in two separate sterile containers and send to the laboratory, for blood sugar levels and lipid profile. Fasting blood sugar level $\geq 110 \mathrm{mg} / \mathrm{dl}$ is considered as raised blood sugar or deranged blood sugar which is one of the risk factors. Total blood cholesterol level $\geq 200 \mathrm{mg} / \mathrm{dl}$, LDL level $\geq 100 \mathrm{mg} / \mathrm{dl}$, triglyceride (TG) level $\geq 150 \mathrm{mg} / \mathrm{dl}$, and HDL level $<40 \mathrm{mg} / \mathrm{dl}$ were considered as dyslipidemia and risk factors for CHD.

\section{RESULTS}

Table 1 shows the sociodemographic profile of the participants. Maximum participants (38.58\%) belonged to the age group of 2535 years and $11.72 \%$ of the participants belonged to the age group of more than 55 years. About $58 \%$ of the participants were female. More number of participants (45.43\%) belongs to lower class of SES, followed by middle (40.57\%) and upper class (14\%). Nearly $17 \%$ of the participants were illiterate and $35.43 \%$ of the participants studied till primary education, followed by graduation and higher $21.14 \%$.

Table 2 presents highly significant association between blood sugar level of study participants and the level of total cholesterol status. It indicates those who have high blood sugar also had high total cholesterol level. Similarly, there was a significant association between blood pressure and total cholesterol status. Those participants who had high blood pressure also had high total cholesterol level. We also observed a significant association between BMI and total cholesterol level; it indicates that obese persons had high total cholesterol status. We did not get any significant association between smoking and total cholesterol level. Furthermore, no significant association was observed between alcohol consumption and total cholesterol level in our study.

Table 3 summarizes no significant association among the risk factors of CHD such as smoking, alcohol, blood pressure, blood sugar, and BMI with HDL level.

Table 4 shows highly significant association between the BMI of study participants and LDL status; it indicates that obese person had high LDL level. Similarly, the significant association was observed between blood sugar and LDL level. No significant association was observed between smoking and LDL level. Similarly, no significant association was observed between alcohol consumption and blood pressure with LDL level.

Table 5 presents a significant association among the risk factors of CHD such as smoking, alcohol, blood sugar, and BMI with TG level. No association was observed between blood pressure and TG level.

\section{DISCUSSION}

Cigarette smoking is an important and independent risk factor of CHD. Smoking adversely affects the concentration of the plasma lipids and lipoprotein levels. A study done by Alharbi [8] on the influence of cigarette smoking on lipid profile observed no significant association between serum cholesterol level among smoker and non-smoker. However, all other components of lipid profile (LDL, HDL, and TG) were found significantly increased for smokers. Prevalence of hypertension was more in females with advancing age and with the exposure to risk factors, i.e., alcohol and smoking in a study conducted by Venkataram et al. [9]. A similar type of study done by Devaranavadgi et al. [10] on the effect of cigarette smoking on blood lipids, in Belgaum, Northern 
Karnataka, India, observed the mean value of serum total cholesterol, serum LDL-cholesterol (LDL-C), and serum TG in cigarette smokers is significantly higher as compared to non-smokers. Another study done by Rao on the effect of chronic tobacco smoking and chewing on the

Table 1: Sociodemographical profile of participants $(n=350)$

\begin{tabular}{lll}
\hline Variables & Categories & n (\%) \\
\hline Age group (year) & $25-35$ & $135(38.58)$ \\
& $>35-45$ & $115(32.85)$ \\
& $>45-55$ & $59(16.85)$ \\
& $>55$ & $41(11.72)$ \\
Gender & Male & $147(42)$ \\
SES & Female & $203(58)$ \\
& Lower class & $159(45.43)$ \\
Education & Middle class & $142(40.57)$ \\
& Upper class & $49(14)$ \\
& Illiterate & $59(16.86)$ \\
& Primary & $124(35.43)$ \\
& Secondary & $60(17.14)$ \\
& Higher secondary & $33(9.43)$ \\
& Graduate and higher & $74(21.14)$ \\
\hline
\end{tabular}

SES: Socioeconomic status

Table 2: Association of risk factors of CHD with total cholesterol level

\begin{tabular}{|c|c|c|c|}
\hline \multirow[t]{2}{*}{ Variables } & \multicolumn{2}{|c|}{$\begin{array}{l}\text { Total cholesterol } \\
\text { status }(n=350)\end{array}$} & \multirow[t]{2}{*}{$p$ value } \\
\hline & Normal (n) & Abnormal (n) & \\
\hline \multicolumn{4}{|l|}{ Smoking } \\
\hline Smoker & $22(68.75)$ & $10(31.25)$ & \multirow[t]{2}{*}{0.611} \\
\hline Non-smoker & $232(72.95)$ & $86(27.05)$ & \\
\hline \multicolumn{4}{|l|}{ Alcohol } \\
\hline Alcoholic & $28(77.77)$ & $8(22.23)$ & \multirow[t]{2}{*}{0.459} \\
\hline Non-alcoholic & $226(71.97)$ & $88(28.03)$ & \\
\hline \multicolumn{4}{|l|}{ Blood sugar } \\
\hline Normal & $230(75.66)$ & $74(24.34)$ & \multirow[t]{2}{*}{0.0008} \\
\hline Deranged & $24(52.17)$ & $22(47.83)$ & \\
\hline \multicolumn{4}{|l|}{ Blood pressure } \\
\hline Normal & $209(76.55)$ & $64(23.45)$ & \multirow[t]{2}{*}{0.001} \\
\hline Hypertension & $45(58.44)$ & $32(41.56)$ & \\
\hline \multicolumn{4}{|l|}{ BMI } \\
\hline Normal & 157 (77.33) & $46(22.67)$ & \multirow[t]{2}{*}{0.018} \\
\hline Overweight/obese & $97(65.98)$ & $50(34.02)$ & \\
\hline
\end{tabular}

Table 3: Association of risk factors of CHD with HDL level

\begin{tabular}{|c|c|c|c|}
\hline \multirow[t]{2}{*}{ Variables } & \multicolumn{2}{|c|}{ HDL level $(n=350)$} & \multirow[t]{2}{*}{ p value } \\
\hline & Normal (n) & Abnormal (n) & \\
\hline \multicolumn{4}{|l|}{ Smoking } \\
\hline Smoker & $16(50)$ & $16(50)$ & \multirow[t]{2}{*}{0.114} \\
\hline Non-smoker & $204(64.15)$ & $114(35.85)$ & \\
\hline \multicolumn{4}{|l|}{ Alcohol } \\
\hline Alcoholic & $24(66.66)$ & $12(33.34)$ & \multirow[t]{2}{*}{0.617} \\
\hline Non-alcoholic & $196(62.42)$ & $118(37.58)$ & \\
\hline \multicolumn{4}{|l|}{ Blood sugar } \\
\hline Normal & $191(62.82)$ & $113(37.18)$ & \multirow[t]{2}{*}{0.977} \\
\hline Deranged & $29(63.04)$ & $17(36.96)$ & \\
\hline \multicolumn{4}{|l|}{ Blood pressure } \\
\hline Normal & $174(63.74)$ & $99(36.26)$ & \multirow[t]{2}{*}{0.521} \\
\hline Hypertension & $46(59.74)$ & $31(40.26)$ & \\
\hline \multicolumn{4}{|l|}{ BMI } \\
\hline Normal & $130(64.04)$ & $73(35.96)$ & \multirow[t]{2}{*}{0.590} \\
\hline Overweight/obese & $90(61.22)$ & $57(38.78)$ & \\
\hline
\end{tabular}

Figures in parenthesis indicate percentages. CHD: Coronary heart disease, BMI: Body mass index, HDL: High-density lipoprotein lipid profile showed decreased levels of HDL cholesterol and increased levels of total cholesterol, LDL cholesterol, and TG in smokers as compared to those in non-smokers [1]. However, in our study, we did not get any significant association between smoking and blood total cholesterol level, smoking with blood HDL level and LDL level. However, we observed a significant association between smoking and blood TG level.

The complex relationship between alcohol use and lipid profile has been documented by earlier studies. The influence of alcohol on lipid metabolism is to be attributed to the transient changes in lipid metabolism. Our study result is consistent with the study of Vaswani et al. who observed TG was higher in alcohol dependents as compared to non-dependent [11]; however, in contrast to our findings, there was no significant association observed among alcohol consumption and blood total cholesterol level. A study done by Riuidavets et al. [12] found that blood levels of HDL-C increased with increased alcohol intake. Similarly, a study conducted by Barboriak et al. showed significantly higher HDLcholesterol (HDL-C) levels in the alcoholic group [13]. They also noticed that, after 2 weeks of alcohol abstinence, the HDL-C levels decreased to normal range. A study done by Choudhary et al. found higher serum HDL-C in heavy alcohol drinkers [14]. However, in our study, there was no significant association observed between alcohol consumption and blood HDL level.

Table 4: Association of risk factors of CHD with LDL level

\begin{tabular}{llll}
\hline Variables & \multicolumn{2}{c}{ LDL level (n=350) } & \multirow{2}{*}{ p value } \\
\cline { 2 - 3 } & Normal (n) & Abnormal (n) & \\
\hline $\begin{array}{l}\text { Smoking } \\
\quad \text { Smoker }\end{array}$ & $11(34.37)$ & $21(65.63)$ & 0.091 \\
$\quad$ Non-smoker & $159(50)$ & $159(50)$ & \\
$\begin{array}{l}\text { Alcohol } \\
\quad \text { Alcoholic }\end{array}$ & $16(44.44)$ & $20(55.56)$ & 0.600 \\
$\quad$ Non-alcoholic & $154(49.04)$ & $160(50.96)$ & \\
Blood sugar & $157(51.64)$ & $147(48.36)$ & 0.003 \\
$\quad \begin{array}{l}\text { Normal } \\
\text { Deranged }\end{array}$ & $13(28.26)$ & $33(71.74)$ & \\
Blood pressure & $140(51.28)$ & $133(48.72)$ & 0.056 \\
$\quad \begin{array}{l}\text { Normal } \\
\text { Hypertension }\end{array}$ & $30(38.96)$ & $47(61.04)$ & \\
BMI & $116(57.14)$ & $87(42.86)$ & 0.0001 \\
$\quad \begin{array}{l}\text { Normal } \\
\text { Overweight/obese }\end{array}$ & $54(36.73)$ & $93(63.27)$ & \\
\hline $\begin{array}{l}\text { Figures in parenthesis indicate percentages. CHD: Coronary heart disease, } \\
\text { BMI: Body mass index, LDL: Low-density lipoprotein }\end{array}$ &
\end{tabular}

Table 5: Association of risk factors of CHD with TG level

\begin{tabular}{|c|c|c|c|}
\hline \multirow[t]{2}{*}{ Variables } & \multicolumn{2}{|c|}{ TG level $(n=350)$} & \multirow[t]{2}{*}{ p value } \\
\hline & Normal (n) & Abnormal (n) & \\
\hline \multicolumn{4}{|l|}{ Smoking } \\
\hline Smoker & $12(37.5)$ & $20(62.5)$ & \multirow[t]{2}{*}{0.002} \\
\hline Non-smoker & 207 (65.09) & 111 (34.91) & \\
\hline \multicolumn{4}{|l|}{ Alcohol } \\
\hline Alcoholic & $16(44.44)$ & $20(55.56)$ & \multirow[t]{2}{*}{0.017} \\
\hline Non-alcoholic & $203(64.64)$ & $111(35.36)$ & \\
\hline \multicolumn{4}{|l|}{ Blood sugar } \\
\hline Normal & $199(65.46)$ & $105(34.54)$ & \multirow[t]{2}{*}{0.004} \\
\hline Deranged & $20(43.47)$ & $26(56.53)$ & \\
\hline \multicolumn{4}{|l|}{ Blood pressure } \\
\hline Normal & 177 (64.83) & $96(35.17)$ & \multirow[t]{2}{*}{0.099} \\
\hline Hypertension & $42(54.54)$ & $35(45.46)$ & \\
\hline \multicolumn{4}{|l|}{ BMI } \\
\hline Normal & 138 (67.98) & $65(32.02)$ & \multirow[t]{2}{*}{0.014} \\
\hline Overweight/obese & $81(55.10)$ & $66(44.90)$ & \\
\hline
\end{tabular}

Figures in parenthesis indicate percentages. CHD: Coronary heart disease, BMI: Body mass index, TG: Triglyceride 
Dyslipidemia is one of the common disorders which are seen in most of the diabetes patients, which causes cardiovascular disorders. In our study, the results showed lipid profile of the diabetics which were higher than that of the non-diabetic. Highly significant association was observed between blood sugar level of the participants and the level of blood total cholesterol status. Similarly, the significant association was observed between blood sugar and blood LDL level and blood sugar with blood TG level. However, no significant association was observed between blood sugar and blood HDL level. Similar results observed by Samatha et al. in their study, i.e., diabetic patients had a higher prevalence of high serum cholesterol, high TG, and high LDL-C than that of controls non-diabetic [15]. The correlation studies showed by Samatha et al. had a negative non-significant correlation $(\mathrm{r}=-0.024)$ between FBG and HDL-C, whereas positive significant correlations were recorded between FBG and TC $(\mathrm{r}=0.584)$ and FBG and TG $(\mathrm{r}=0.514)$ [15].

The results concluded that blood total cholesterol was statistically significant in hypertensive subjects. The result is consistent with the studies of Bamrara et al. [16] and Kanwar et al. [17] who also observed blood total cholesterol was statistically significant in hypertensive patient. However, in our study, LDL and TG were statistically not significant in hypertensive subjects. The result is in contrast with Bamrara et al. [16] and Kanwar et al. [17], and they observed that LDL-C and TG were statistically significant in hypertensive subjects. In a study conducted among Filipinos by Urrutia et al., results showed that females have more risks of developing heart attack than males for patients with hypertension, with diabetes, with a family history of CVD, and those who are smoking [18].

The result of our study in relation to HDL level is in consistent with a study done by Saha et al., who also observed that blood HDL level was statistically not significant in hypertensive patient [19].

The dyslipidemia associated with obesity no doubt plays a major role in the development of CVD in obese individuals. Ranganathan et al. in their study observed that the total cholesterol, the LDL, and the TGs are found to be relatively high among the subjects with high BMI when compared with normal BMI persons, and this difference was found to be statistically significant, whereas HDL cholesterol had not shown any significant difference between the two groups [18]. Our study findings showing significant association of BMI with total cholesterol, LDL, and TGs and non-significant association between BMI and HDL level were similar to of Ranganathan et al. study [20]. Shamai et al., in their study, assessed the relationship between BMI and lipid fractions. They observed that higher BMI was inversely associated with HDL and directly associated with TG. BMI showed no significant association with LDL [21].

\section{CONCLUSION}

In this study, we tried to show how the various risk factors of CHD such as smoking, diabetes, obesity, hypertension, and alcoholism are associated with lipid profile (total cholesterol, HDL, LDL, and TG level). From the study, we concluded that blood sugar, blood pressure, and BMI are significantly associated with total cholesterol level. Blood sugar and BMI are significantly associated with LDL level. Smoking, alcohol, blood sugar, and BMI significantly associated with TG level. However, in our study, we did not get any significant association between smoking and total cholesterol level, smoking with HDL and LDL level, which is in contrast with other study. Therefore, studies with a larger sample size are required to confirm these results. Further, this study has shown that lipid abnormalities are associated with various risk factors for CHD. It indicates that treatment of CHD in a patient should include correction of dyslipidemia and other risk factors. Hence, a community-based education in this regard is of utmost importance.

\section{REFERENCES}

1. Rao SC, Emmanuel SY. The effect of chronic tobacco smoking and chewing on the lipid profile. J Clin Diagn Res 2013;7:31-4.

2. Deji LY, Stigum H, Chongsuvivatwong V. Lipid profile and its association with risk factors for coronary heart disease in the highlanders of Lhasa, Tibet. High Alt Med Biol 2011;12:57-63.

3. Akbari MZ, Bhatti MS, Shakoor M. Lipid profile in smoking. J Appl Math Comput 2000;12:19-21.

4. Mohan V, Deepa R, Rani SS, Premalatha G. Prevalence of coronary artery disease and its relationship to lipids in a selected population in South India. Am Coll Cardiol 2001;38:682-7.

5. Diabetes, Heart Disease and Stroke-National Diabetes Information Clearinghouse (NDIC). Available from: http://www.diabetes.niddk.nih. gov/dm/pubs/stroke.

6. Reaven GM, Lithell H, Landsberg L. Hypertension and associated metabolic abnormalities: The role of insulin resistance and the sympatho-adrenal system. N Engl J Med 1996;334:374-81.

7. Wilson PW, Agostino RB, Levy D, Belanger AM, Silbershatz H, Kannel WB. Prediction of coronary heart disease using risk factor categories. Circulation 1998;97:1837-47.

8. Alharbi WD. Influence of cigarette smoking on lipid profile in male university students Pakistan. J Pharmacol 2011;28:45-9.

9. Venkataram R, Kumar BP, Kumarswamy M, Singh R, Pandey M, Tripathy $\mathrm{P}$, et al. Smoking, alcohol and hypertension. Int J Pharm Pharm Sci 2013;5:28-32

10. Devaranavadgi BB, Aski BS, Kashinath RT, Hundekari IA. Effect of cigarette smoking on blood lipids-a study in Belgaum, Northern Karnataka, India. Global J Med Res 2012;12:57-61.

11. Vaswani M, Rao RV. Biochemical measures in the diagnosis of alcohol dependence using discriminate analysis. Indian J Med Sci 2005;59:423-30

12. Ruidavets JB, Ducimetiere P, Arveiler D. Types of alcoholic beverages and blood lipids in a French population. J Epidemiol Community Health 2002;56:24-8.

13. Barboriak JJ, Jacobson GR, Cushman P. Chronic alcohol abuse and high density lipoprotein cholesterol. Alcohol Clin Exp Res 1980;4:346-9.

14. Choudhary SR, Ueshima H, Kita Y. Alcohol intake and serum lipids in a Japanese population. Int J Epidemiol 1994;23:940-7.

15. Samatha P, Venkateswarlu M, Prabodh VS. Lipid profile levels in Type 2 diabetes mellitus from the tribal population of Adilabad in Andhra Pradesh, India. J Clin Diagn Res 2012;6:593-6.

16. Bamrara P, Mittal Y, Mathur A. Evaluation of lipid profile of North Indian hypertensive subjects. Biomed Pharm Sci 2013;3:38-41.

17. Kanwar G, Jain N, Kirad S, Yadav M. A study on serum lipid profile in hypertensive patients of Hadoti region. Int J Res Appl Nat Soc Sci 2014;2:53-60.

18. Urrutia JD, Tampis RL, Mercado J, Baygan AV. Survival analysis for the risk of developing heart attack. Int J Pharm Pharm Sci 2010;8 Suppl 2:6-10.

19. Saha MS, Sana NK, Shaha RK. Serum lipid profile of hypertensive patients in the Northern region of Bangladesh. J Biosci 2006;14:93-8.

20. Ranganathan S, Krishnan TU, Radhakrishnan S. Comparison of dyslipidemia among the normal-BMI and high-BMI group of people of rural Tamil Nadu. Med J DY Patil Univ 2015;8:149-52.

21. Shamai L, Lurix E, Shen M, Novaro GM, Szomstein S, Rosenthal R, et al. Association of body mass index and lipid profiles: Evaluation of a broad spectrum of body mass index patients including the morbidly obese. Obest Surg 2011;21:42-7. 